\title{
Pascal's Pensees : problems of edition, problems of interpretation.
}

Camille Akmut

May 5, 2020

\begin{abstract}
Summary of editorial and interpretative issues - then and now. Cousin's 1842 Report; Pensees as seen by contemporaries up to about Nietzsche...
\end{abstract}




\section{I - Problems of edition}

Modern editions of the Pensees may sometimes give the reader the impression of a unified book;

Older ones made such a false notion more difficult : they held variously, on the front page, or elsewhere, as title or otherwise :

"Thoughts of Mr. Pascal, on religion, and other subjects, having been discovered after his death amongst his papers [reviewed and corrected anew/once more]"

such as this one from 1694 (published in Lyon).

In fact they were fragments, many of them. He [Pascal] would also sometimes dictate his thoughts to others ${ }^{1}$.

Victor Cousin ${ }^{2}$, more than anyone, early on, had highlighted the many issues surrounding the Pensees.

His Report to the French Academy from 1842 remains an important reading for anyone wishing to understand this work's complicated nature and background.

These problems can be summed up as, generally :

- Uncertain order of the notes/thoughts (dubious existing classifications)

- Early editions diverge from the Manuscript; alterations

- What sources and classification to use, in the future.

- [Hard to read, decipher the Manuscript ${ }^{3}$ - the least of issues?]

Among these problems emerges as the most dramatic : suppressions (in

\footnotetext{
${ }^{1}$ This last information we gathered from Cousin's report (p. 10).

219 th c. philosopher and education administrator.

${ }^{3}$ p. 10 , and e.g. 91 again for a specific example.
} 
addition to omissions), on one hand, combined with alterations or additions on the other, and relocations yet ${ }^{4}$ among others.

They are associated with two editions : the 1669 Port-Royal edition (established by family and friends of Pascal) and Bossut's 1779 one $^{5}$, which served as basis for all other ones and constituted the dominant understanding of Pascal's work.

Here one of Cousin's memorable moments in his report, in this regard :

"Imagine if Plato's original manuscript was - known to all - available in a public library, and yet no one cared, and everyone, year after year, reproduced the same [fake] editions, without ever asking themselves questions; and discussed or admired this or that passage of the Pensees, or finer point of Pascal's thought [based on illusions]. Yet this is exactly where we are when it comes to the Pensees ... Go take a look at the Royal library [on Richelieu street], it's not far away" [and convince yourself of the major differences] ${ }^{6}$

From his Report, two passages can be taken to illustrate this (that struck us as particularly bad) :

- Suppressions

an entire c. 15 lines long passage is simply erased by the P-R editors; in which Pascal expounded on his thought "Montaigne was wrong; customs should only be followed because they are customs, not because they are reasonable..."7

- Additions

${ }^{4} \mathrm{As}$ in the case of Bossut, who put a fragment as supplementary material (Cousin report 46) (See also p. 208 for a Port-Royal relocation.)

${ }^{5}$ Charles Bossut (1730-1814)

${ }^{6}$ Pp. $9 \mathrm{ff}$.

${ }^{7}$ Cousin 1842 : 168-169. (P-R "a supprime tout ce morceau") 
it gets even worse; a single sentence of Pascal, in turn, [the one on Pyrrhus receiving advice on rest (not needing a conquest)], is turned into a page! once passed through the hands of the most zealous P-R editors... ${ }^{8}$

139 B / Manuscript p10

"The advice that had been given to Pyrrhus to take the rest he was seeking through a many [hardous tasks], met great difficulties."

Port Royal

"That is why when Cineas told Pyrrhus, who had proposed to take his rest amongst friends once done conquering the World, that it would be better to enjoy his happiness now" etc. etc. etc.

In Cousin's view, an authentic version of the Pensees could be found in the intersection of the two dominant editions (of his time) and the Manuscript ${ }^{9}$ :

$\{$ Port-Royal ed. $\} \cap\{$ Bossut ed. $\} \cap\{$ Manuscript $\}=$ the 'real' Pensees...

He estimated, to have established "irrefutably", that one quarter up to one third of the Pensees (as they were commonly understood to be) were foreign to that work. ${ }^{10}$

Cousin also mentions errors of Pascal corrected by P-R; those corrections he judges favorably. ${ }^{11}$

To give one example : at some point Pascal addresses a possibly real person, in what appears to be an attack, and Cousin agrees with P-R this should not be included (in that great work...). This is contestable.

\footnotetext{
${ }^{8}$ Cousin $1842: 105$.

${ }^{9}$ Cousin 1842: 71

${ }^{10}$ Cousin 1842 : 70. See also p. 24 for more details on the same.

${ }^{11}$ Cousin 1842 : c. pp. 90-91.
} 
On the other hand, when Pascal himself strikes through some of his own passages e.g.

924 B / Manuscript p344

"People with no word, no faith... two hearts, and the same ambiguity

in their language; like the faboulous amphibian animal. Half-birds, half-fishes."

Cousin feels they should stay ("On ne voit pas pourquoi" etc. etc.) ${ }^{12}$.

Not everything done by Cousin was perfect, and yet he created the first modern, scientific edition, and contributed to a major leap in our understanding of Pascal's complicated work.

[To say nothing of English translations, and delays in Pascal's reception in the English-speaking world.

That e.g. Russell may have been ignorant of Pascal comes both out of lack of knowledge and stupidity i.e. he had not had sufficient access to Pascal's work and hated him. Increasingly it appears to us that all that Russel may have known of Pascal was whatever he had read in Nietzsche... (And, even Nietzsche he might have read in the wrong places...)]

\section{II - Interpretative problems, Contemporaries to Nietzsche}

In 1670, Etienne Perier, the son of Pascal's sister (not to be confused with the other Etienne, father of Blaise), wrote a preface for the Pensees, noting :

"M. Pascal, having left the study of mathematics at a young age, and of physics, and the other profane sciences, in which he had made

\footnotetext{
${ }^{12}$ Cousin 1842 : 200.
} 
such considerable progress, and such that no one could claim to have gone as far as he had in the matters that were his, begun, around his thirstiest year, to apply himself to more serious and elevated matters".

Religion and its study was meant.

This was proposed as interpretation, following the death of Etienne's grandfather a few years earlier.

Some centuries later a provincial professor sought to revolutionize the understanding of the Pensees, this seemed very important to him for he made sure to specify the year that this idea had been proposed by him (a now obscure figure) :

"I attack the traditional thesis : that the Pensees, had Pascal had the time to complete them, would have been an apology of Catholicism, and only that"

And, yet, Souriau merely attempted to debate the finer points of religious controversies : in his view the Pensees aimed to establish the "truth" of Jansenism, as part of a dogmatic section, and to defend Port-Royal against its enemies, in a more polemical one. ${ }^{13}$

Cousin himself noted that Pascal's project was vast enough ["son dessein"] to include the most diverse of thoughts ${ }^{14}$.

Boutroux, addressing another commentator of Pascal, noted how (about) everyone were able to find their own ideas in Pascal. ${ }^{15}$

In the view of Cousin it was Descartes who put an end to philosophy and literature (as they had been organized hitherto in the Renaissance), through formal innovations (by his language, e.g. abandonment of pomp), but Pascal who pushed this breach with tradition the furthest. ${ }^{16}$

\footnotetext{
${ }^{13}$ Souriau $1896: 5$ (and surrounding)

${ }^{14}$ Cousin $1842: 22$

${ }^{15}$ Letter to Giraud. (Cited in Giraud 1905 : vii)

${ }^{16}$ Report, pp. 4-5.
} 
By the time the cleverest-of-all Nietzsche came along, Pascal was pronounced dead and buried, and unburied, a thousand times over again.

"The greatest and most deplorable example" of what Christianity could do to a thinker...

Relegated forever to the back pages of history.

Russell used the dead Nietzsche to hammer on the even more dead Pascal.

\section{III - More positive things?}

We stated that many end up gravitating towards Pascal : should people look at Pascal for philosophical guidance?

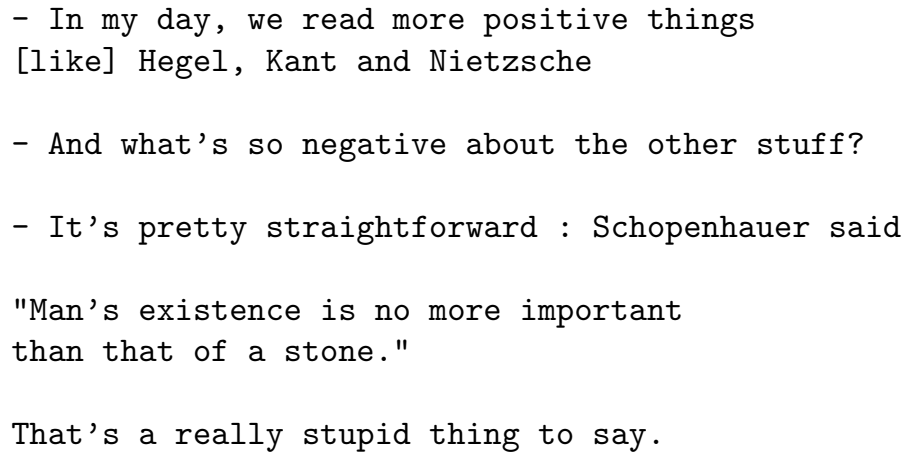

17

This is dialogue from The third generation, whose themes cover technology, including computers and philosophy ${ }^{18}$ :

But, if this were a work of the French new wave Pascal might have very well replaced Schopenhauer's role.

\footnotetext{
17 [Adapted and revised from random Blu-ray subtitles.]

${ }^{18}$ For capitalistic reasons, a computer technology entrepreneur funds a terrorist group (by 'third generation' contemporaries knew the RAF was meant) in times of "“alarmism against mass data collection"" ("Hetze") - as he put it. (Another Schopenhauer quote serves as secret/code.)
} 
If indeed "we all live in a great asylum for the insane" as Pascal purportedely expressed $^{19}$ - then none of this should matter.

$414 \mathrm{~B}$

"... to not be insane would be insane by some other turn of folly."

[It would be crazy to not be crazy $]^{20}$

he did write.

A thought that should in turn make him appealing (again) for anarchists.

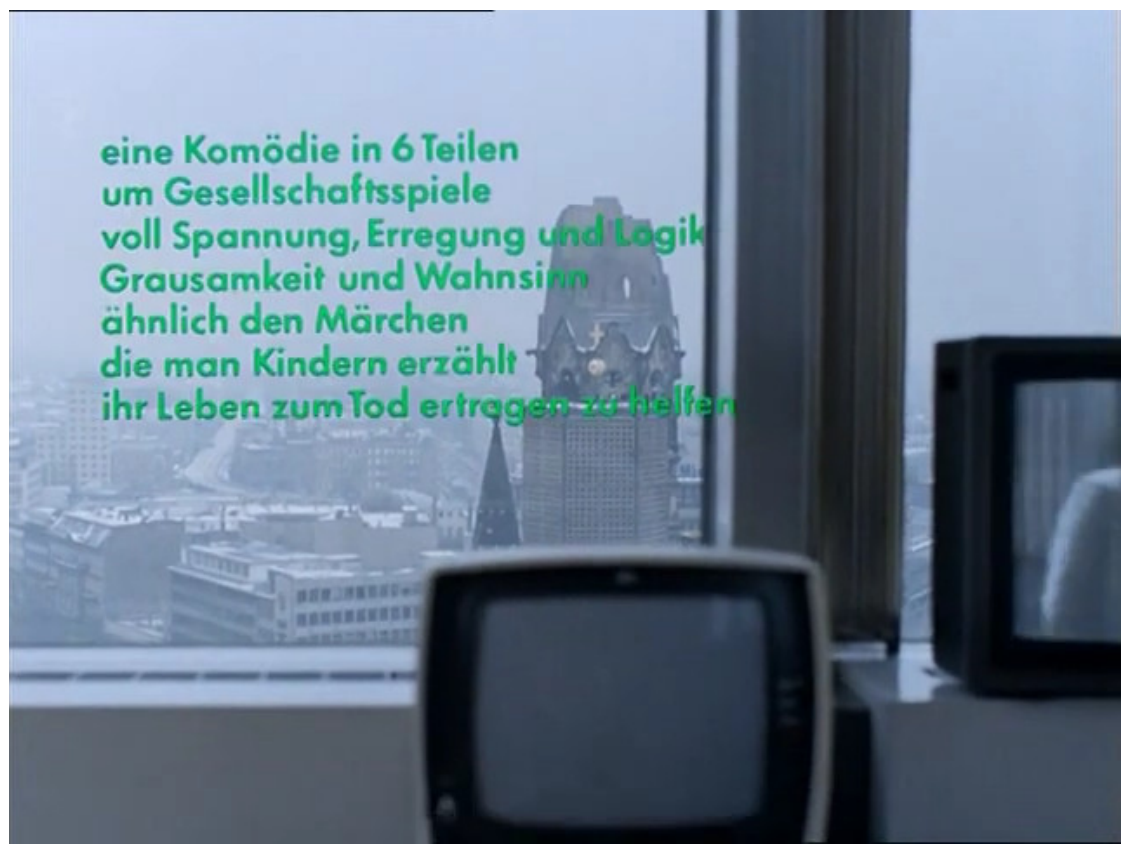

\footnotetext{
${ }^{19}$ Found in the introduction to Celine's Semmwelweis (all ways strangely lead back to Pascal). Possibly an interpretation of $82,331,414 \ldots$ [Pascal wrote a lot on folly]

${ }^{20}$ Huxley, using the work of social psychologists, would later echo these thoughts.
} 
To all of them, Pascal would have answered, and did answer already :

Manuscript $\mathrm{p} 61$

"Atheism, sign of a strong mind, but only to a certain degree."

Nietzsche, so clever and well-read and knower of so many languages, thought he had understood the poor Pascal better than he himself had done, but not quite so;

It had not escaped Pascal what complicated situation he was in, and yet :

For Pascal, believing was hard, while not believing was easy...

Marxists and anarchists alike should find in Pascal a new companion :

Just like them he had accepted the importance of making uncompromising choices. 